\title{
Sports Medicine
}

\section{Nutritional Support for Athletic Performance}

\author{
Guest Editor \\ Lawrence L. Spriet \\ Department of Human Health and Nutritional Sciences, \\ University of Guelph, Ontario, Canada
}

Peer Reviewers

The Guest Editor of the supplement selected peer reviewers for each paper and managed the process.

We would like to thank the peer reviewers who provided valuable contributions to individual papers.

The supplement was supported by Gatorade Sports Science Institute.

Conflicts of Interest: The supplement was guest edited by Lawrence L. Spriet who attended a meeting of the Gatorade Sports Science Institute (GSSI) Expert Panel in March 2014 and received honoraria from the GSSI, a division of PepsiCo, Inc., for his meeting participation. He has not received any honoraria for guest editing the supplement. Lawrence L. Spriet selected peer reviewers for each paper and managed the process. 